\title{
Higher Order Vagueness in a Dynamic Landscape: Multi-Resolution Morphometric Analysis of a Coastal Dunefield
}

\author{
P. Fisher ${ }^{1 *}$, J. Wood ${ }^{1}$, and T. Cheng ${ }^{2}$ \\ ${ }^{1}$ Department of Information Science, City University, London EC1V 0HB, United Kingdom \\ ${ }^{2}$ Department of Geomatic Engineering, University College London, Gower Street, London, WC1E 6BT, United Kingdom
}

\begin{abstract}
Many environmental phenomena can be conceptualised as vague and so may be suitable for storage as fuzzy sets and analysis by fuzzy logic. Fuzzy sets directly address the vagueness in the information, but many consider that any statement about a vague phenomenon must itself be vague. This is known as higher order vagueness, and is handled in fuzzy set theory by type- 2 and, by extension, type-n fuzzy sets. In this paper we use the recognition of, and change in, a system of coastal sand dunes as an environmental example in which to explore the use of type-2 fuzzy sets. The crests and troughs of the dunes are identified as fuzzy sets from geomorphometric analysis of high resolution digital elevation models from two years (1998 and 2000). By varying the parameters of the morphometric extraction, multiple instances of type-1 fuzzy sets can be defined, and these can be summarised to yield type-2 fuzzy sets. The logic of change analysis is presented, and two alternative approaches to change analysis of type- 2 fuzzy sets implemented. In one approach changes in the multiple instances of type-1 fuzzy sets are analysed and summarised as type- 2 sets. The second approach directly examines change in the parameters of type- 2 fuzzy sets, viewing the results for the different parameters as separate instances of change. All analyses produce satisfactory results which, although they are hard to verify, make sense, yielding a range of possible but small degrees of fuzzy change. In a rather sedentary dune system (as is usual in a coastal location in mid-latitudes) this is to be expected. Change analysis in most applications of type-2 fuzzy sets, which might be based on expert advice for defining memberships, would have to rely on this second approach, and it is therefore interesting to note that this yields the largest range of possible change results.
\end{abstract}

Keywords: Dynamic landforms, fuzzy logic, morphometry, multi-resolution analysis, sand dunes, type-2 fuzzy sets

\section{Introduction}

Fuzzy sets have been widely suggested as a basis for the representation of vague phenomena (Klir and Yuan, 1995; Kruse et al., 1994; Mendel, 2001; Ross, 2004). The representation of environmental phenomena as fuzzy sets (Fisher, 2000a, b; Petry et al., 2005; Robinson, 2003) has included soils (Burrough, 1989; Lagacherie et al., 1997) vegetation (Moraczewski, 1993a, b), geology (Brown et al., 2003; Luo and Dimitrakopoulos, 2003), land cover classification from remotely sensed data (Foody, 1992, 1996), landform classes (Cheng and Molenaar, 1999; MacMillan et al., 2000), and been extended to the agent-based modelling of the ecological movement of animals (Robinson and Graniero, 2005; Elith et al., 2002). Most research has been grounded in the argument that many class descriptions for natural resources are inherently vague. Moraczewski (1993a), for example, identified the linguistic vagueness in textual descriptions of vegetation classes. Similarly, Campbell (1977) showed gradual change in soil properties across a mapped boundary between two soil types. Fisher et al. (2004) argued that vagueness of class was also related to the difference in outcome of analysis with spatial resolution. Thus in either spatial or attribute dimensions,

\footnotetext{
*Corresponding author: pff1@soi.city.ac.uk
}

or at any single resolution of analysis, it is hard or impossible to draw a precise boundary around many environmental classes.

While it is argued that fuzzy sets address the problem of vagueness in the allocation of objects to classes, most applications only work with one expression of that vagueness, also known as first order vagueness or type-1 fuzzy sets. A type-1 fuzzy set represents the degree to which an object belongs to a set. Any value of a type-1 set, however, is a precise statement about an object that is thought to be vague. Such precise statements, as a way of describing vague phenomena, are almost paradoxical, and are questioned in the philosophical literature on vagueness. It has been argued that any statement about a vague phenomenon must itself be allowed to be vague (Sorensen, 1985). In philosophy it is an outstanding question whether it is necessarily the case that all such statements must be vague (Sainsbury, 1991; Varzi, 2003; Wright, 1992; Williamson, 1994), but the ability to accommodate this higher order vagueness is considered necessary for any theory of vagueness to be complete (Keefe and Smith, 1996; Kulik, 2003). Within fuzzy set theory, type-2 fuzzy sets are used to accommodate this uncertainty. Instead of the membership of any object in the set being a single value a membership function is used to describe the distribution of possible values (Figure 1).

Most texts in fuzzy set theory have tended to do little 

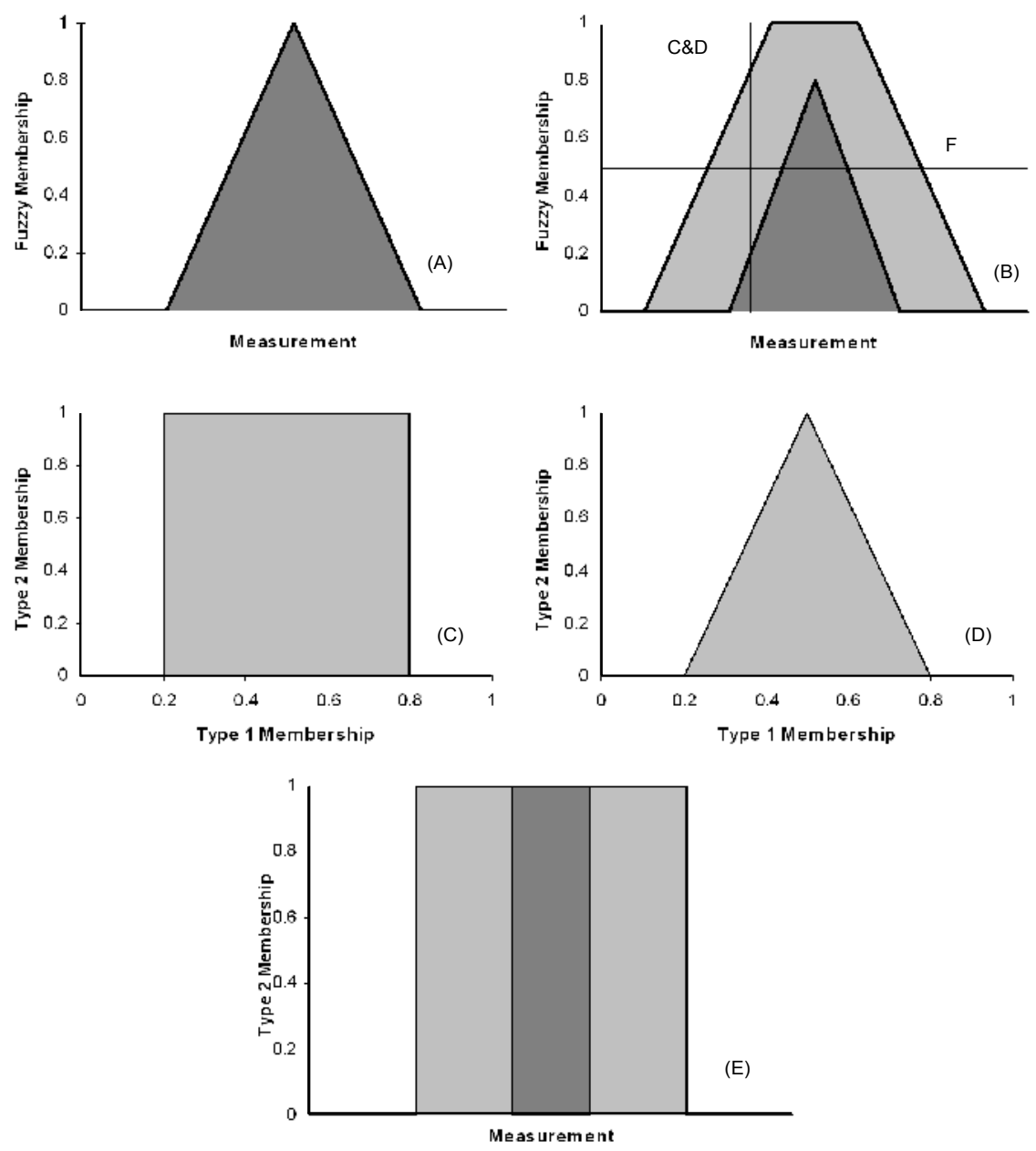

Notes: A type-1 fuzzy membership function (using a triangular example, A) can be modeled as a type-2 fuzzy set (B), where at any value of measurement a single membership value is not recorded, but a distribution of values is recognized; two type-2 fuzzy sets are illustrated along the vertical profile indicated in (B): an interval type-2 set (C) and a triangular type-2 set (D), as well as the horizontal line (or $\alpha$-cut of the type-1 set) in (B) in (E) (Fisher et al., in press).

Figure 1. Different types of fuzzy membership functions.

more than mention the existence of type-2 fuzzy sets (e.g. Klir and Yuan, 1995; Kruse et al., 1994) due to the complexity they introduce to any analysis. However, recent work (John, 1998; Mendel, 2001; Mendel and John, 2002; Mizumuto and Tanka, 1976) has led to the acknowledgement of not only the importance of the concept but also simplification of the mathematics.

Higher order uncertainty has been raised in the geographical information literature by Kulik (2003) within the formalism of supervaluation theory (Fine, 1975, Bennett, 2001). Type-2 fuzzy sets are mentioned by Verstraete et al. (2005) as being possible within their method, although they do not go into any detail, while Du and Zhu (2006) give a theoretical treatment for type-2 spatial fuzzy sets. On the other hand, previous research by Fisher et al. (in press) has directly explored methods for populating type-2 fuzzy sets for spatial informa- tion. They used multi-scale fuzzy modelling of morphometric peaks as a way of determining the spatial extents of the peakness as fuzzy sets (Fisher et al., 2004; discussed further in section 2).

In the present research we again apply mutli-scale analysis of morphometric classes to derive type-1 and type- 2 fuzzy sets. Here we use multi-temporal digital elevation models of a coastal dunefield in northwest England. As with most work with multi-temporal datasets we focus on the possibility of doing change analysis, but in the study presented here the change analysis is of the vague interpretation of the landscape of the dunes modelled as type-1 and type-2 fuzzy sets.

In section 2 we review the recognition of landform classes in elevation models as fuzzy sets. In section 3 we outline the general method of analysis, and the relevant fuzzy set theory. We describe the study area in section 4 , and an analysis of 
type- 1 and type- 2 fuzzy sets is presented in sections 5 and 6 . Finally, section 7 presents discussion, conclusions and suggestions for further work.

\section{Fuzziness of Landform Classes}

Information derived from the Digital Elevation Models (DEMs) is widely used in the analysis of terrain. Among the simpler outcomes of terrain analysis is the assignment of a location to a geomorphometric unit: pit, peak, pass, channel, ridge, and plane (Evans, 1979, 1980; Peucker and Douglas, 1975; Wood, 1996b). However, a number of researchers have introduced the idea that terrain objects are fundamentally vague (Sainsbury, 1989, 1995; Varzi, 2001; Williamson, 1994), being hard to define meaningfully in terms of either their elevation or their spatial extent (Usery, 1996; Wood, 1996a, b; Fisher and Wood, 1998). Furthermore, it has been suggested that they may be appropriate for analysis by fuzzy sets. To actually define vague landscape features, researchers have used either a number of surface derivatives, such as slope and curvature, in multivariate fuzzy clustering (Burrough et al., 2000; Irvin et al., 1997; MacMillan et al., 2000), or they use elevation-based fuzzy membership functions where the degree to which any point is similar to the morphometric concept is measured only by the elevation at that point as specified in a semantic import model (Cheng and Molenaar, 1999; Usery, 1996). These methods all work at the resolution of the DEM.

In presenting the change in the fuzzy coastal landforms Cheng and Molenaar (1999) show that it is possible to model those landforms with fuzzy sets using the semantic import model relating fuzzy membership simply to height above the datum. They identify beach, foreshore and dune area as fuzzy objects, and explore the evolution of those fuzzy objects providing greatly enhanced and more realistic results from the analyses than might be achieved in a Boolean treatment. Their fuzzy set membership functions are parameterised by consultation with experts as to the height at which different landscape units occur. They show that this approach works in the beach environment where the dominant landforms can be modelled by analysis of the elevation with respect to sea level where form and process are dominated by the movement of the sea. Among the dunes which are beyond the direct influence of the sea, however, the analysis is less useful. Indeed, a small area surrounded by dunes is classified as foreshore (Cheng and Molenaar, 1999) which is inconsistent with the geomorphology. The problem arises because the fuzzy membership determination is not designed to recognise either dunes or features of a dune field.

In the work reported here we are concerned to identify the coastal dunes based on elevation, and so an approach tuned to dune recognition is required. The surface morphology of dunes is composed of ridges along the crest of the dunes, troughs between dunes and planar slopes to both windward and leeward of the crest (the windward slope usually being steeper) (Pethick, 1984). If dunes are infrequent, the inter-dune areas can be more extensive and better described as planar (indeed nearly flat) slopes. The six morphometric classes identified by Evans (1972) and Wood (1996) can be rationalised into elements of dunes. Thus in a dune field the morphometric classes ridges and peaks are both part of the dune crest and channels and pits are part of the inter-dune troughs. Planar slopes are the leeward and windward slopes. Only passes are ambiguous since they could be locations on the dune crest or they could be between dunes.

A pixel in a raster grid of elevations can be assigned to a morphometric class, ridge, for example, but a number of questions remain. No landscape feature definable from the elevation at a location captures the full variety of possible causes of vagueness of the assignment of the object to the class. In most analyses the assignment of a grid cell to a morphometric class, as well as the derivation of most of the terrain variables used in the fuzzy clustering mentioned, is actually assessed over a spatial footprint including at least the grid cell focal to analysis and its immediate neighbourhood, but no attempt is made to assess the landforms at any other resolution, and so they only have a meaning specific to the resolution of the measurement. If the resolution of observation is changed, then the morphometric class to which a location is assigned can be expected to change for some locations although not for all. Those where it does not change can be considered to match the central concept of that morphometric class while those where it changes can be considered to be in zones of transition between two or more morphometric classes. Indeed, many locations may be assigned to all six morphometric classes depending solely on the resolution of measurement.

Elsewhere we have demonstrated this approach, by showing that the frequency of occurrence of the different classes can be used to identify the fuzzy membership of the morphometric class (Fisher et al., 2004, 2005). We showed that by analysis of these fuzzy sets of landforms in the English Lake District, and the vicnity of Ben Nevis in Scotland a much greater amount of information can be extracted from the DEM. In essence, it is possible to give a definition of the spatial extent of the vague objects and to develop novel analyses as a consequence. In this paper, we extend this approach to exploring the changing morphometry of a coastal sand dunefield.

\section{Theory and Method of Type-2 Multi-Resolution Fuzzy Analysis}

\subsection{Type-1 Fuzzy Sets From Multi-Resolution Morphometry}

The basic method on which this analysis is based was introduced by Fisher et al. (2004, 2005), and so only the essentials are recapped here. The morphometric class, $L$, at a location, $x$, must belong to the closed set of possible morphometric landforms classes [ridge, peak, pass, channel, pit, planar], which we will indicate by the matrix $[A]$. Thus:

$$
L(x)=[A]
$$

where for any $x[A]$ contains 6 values. 5 values are equal to 0 and one to 1 , being the memberships of the Boolean sets of the six morphometric classes, $A$ (denoted by $m_{A}(x)$ ). However, the morphometric class is not necessarily stable under repea- 
ted classification at different resolutions (Wood, 1996a, b). Thus $[\boldsymbol{A}]_{\mathrm{s} 1}$ is not necessarily equal to $[\boldsymbol{A}]_{\mathrm{s} 2}$ or to $[\boldsymbol{A}]_{\mathrm{s} 3}$, where $\mathrm{s} 1, \mathrm{~s} 2$, and s3 indicate different measurement resolutions. Indeed, this variability under changes in resolution is one of the reasons that the assignment of any location to a morphometric class should be considered vague, and is therefore exploited as a basis of populating the fuzzy sets for those morphometric classes. Specifically, the membership of a particular fuzzy morphometric class can be given as:

$\mu_{A}(x)=\frac{\sum_{i=1}^{n} m_{A}(x)_{s_{i}}}{n}$

where $\mu_{A}(x)$ is the fuzzy membership of morphometric class $A$ at $x$, and $n$ is the number of resolutions of analysis (Note, if an a priori reason exists different resolutions of Boolean analysis can be associated with alternative weights, but there is no such reason here).

\subsection{Populating Type-2 Fuzzy Sets By Further Dependencies}

The allocation of a pixel to the classes ridge or channel is controlled by a threshold value of curvature, $c$, of the surface. The effect of varying this threshold is to identify a particular ridge or channel as having a larger or smaller areal extent (Wood, 1996b). It is the contention of the research presented here that by varying this threshold value, in multi-resolution analyses, it is possible to populate type- 2 fuzzy sets of ridges and channels. The curvature parameter is a dimensionless value such that $c= \pm 50$ and higher but is commonly in the range $c= \pm 5$ (Wood, 1996b). Furthermore, it is not necessarily the case that all morphometric classes are equal for all valuations of $c$, just as with resolution (section 3.1).

Any one threshold value will yield a particular instance of the type-1 fuzzy set in a multiresolution analysis, and multiple analyses will yield a range of type- 1 sets which can be used to define a type- 2 set. Thus if $\mu_{A}(x)_{c}$ is the fuzzy membership of a cell in morphometric class $A$ at location $x$ given a threshold for curvature $c$, then the value of $\mu_{A}(x)_{c l}$ is not likely to be equal to $\mu_{A}(x)_{c 2}$. Furthermore, if $m$ values of $c$ are used $\left(c_{1}, c_{2}, \ldots, c_{m)}\right.$ a number of different types 1 fuzzy sets are determined, which themselves are instances of the type-2 fuzzy set and can be used to describe that type- 2 set, indicated by $\mu_{2 A}(x)$. The simplest parameters of the type- 2 fuzzy set are the minimum and maximum memberships (Equations $3 \mathrm{a}$ and $3 \mathrm{~b}$ ) which could be seen as equivalent to the bounds of interval type-2 fuzzy set. Using the mean of the type-1 fuzzy memberships (Equation 3c) as a parameter of central tendency allows the description of a triangular type-2 fuzzy membership function (the median or mode could be used) (Fisher et al., in press). With sufficient instances of the type-1 fuzzy sets, it should be possible to derive the full distribution of the type-2 fuzzy membership:

$\mu_{2 \max }(x)=\max _{j=1}^{m} \mu_{j}(x)$ $\mu_{2 \min }(x)=\min _{j=1}^{m} \mu_{j}(x)$

$\mu_{2 \text { mean }}(x)=\sum_{j=1}^{m} \frac{\mu_{j}(x)}{m}$

It should be noted that Equation 3a returns the usual union of the $m$ type- 1 fuzzy sets, and Equation $3 b$ returns the usual intersection of those sets.

\subsection{Dune Crests and Dune Troughs}

As noted in Section 2, sand dunes have three key morphometric components: the crest of the dune, the trough between dunes and the planar slopes between the crest to the trough. Attention here is focussed on the dune-crest and the dunetrough, being respectively the union of the memberships of the ridge and the peaks in the dunefield and the union of the channels and the pits.

In fuzzy logic, the union is usually taken as the maximum function, but alternative union operators can be defined. Because the fuzzy memberships of the different morphometric classes at any one location always sum to unity, which is also the maximum allowable value of a fuzzy set, it seems more appropriate to determine the union from the bounded sum (Klir and Yuan, 1995). The union of two sets $\mathrm{P}$ and $\mathrm{Q}$ is, therefore, given by Equation 4; the fuzzy membership of the dune crest or crestness (DC), for example, is given when $\mathrm{P}=$ ridge and $\mathrm{Q}=$ peak, and the inter-dune trough or troughness (DT) is given when $\mathrm{P}=$ channel and $\mathrm{Q}=$ pit:

$\mu_{P \cup Q}(x)=\min \left(1, \mu_{P}(x)+\mu_{Q}(x)\right)$

\subsection{Change Analysis}

The logic of spatial change analysis in any context (fuzzy or Boolean) is straight forward, although rarely articulated. It relies on determination of those locations which at time $t 1$ belong to class $\mathrm{c} 1$ and at time $\mathrm{t} 2$ do not. It is a secondary question to ask what class is present at that location at time $t 2$. This interpretation of fuzzy change has been discussed by Deer (1998) and extended by Fisher et al. (2005; Fisher et al., 2006), and so only relevant parts of the theoretical treatment are recapped here.

It is possible to model the movement of a dune-crest in two separate queries (Fisher et al., 2005): (a) the areas which gain dune-crest are given by determining those locations which do not have dune-crest at time $\mathrm{t} 1$ but do at time $\mathrm{t} 2$; it is the membership of both not dune-crest at $\mathrm{t} 1$ AND dune-crest at t2; and (b) those areas which lose dune-crest can be determined as the membership of both dune crest at t1 AND not dunecrest at $\mathrm{t} 2$.

Both queries are answered by an intersection of the two sets concerned: the occurrence at one time and absence at another. 

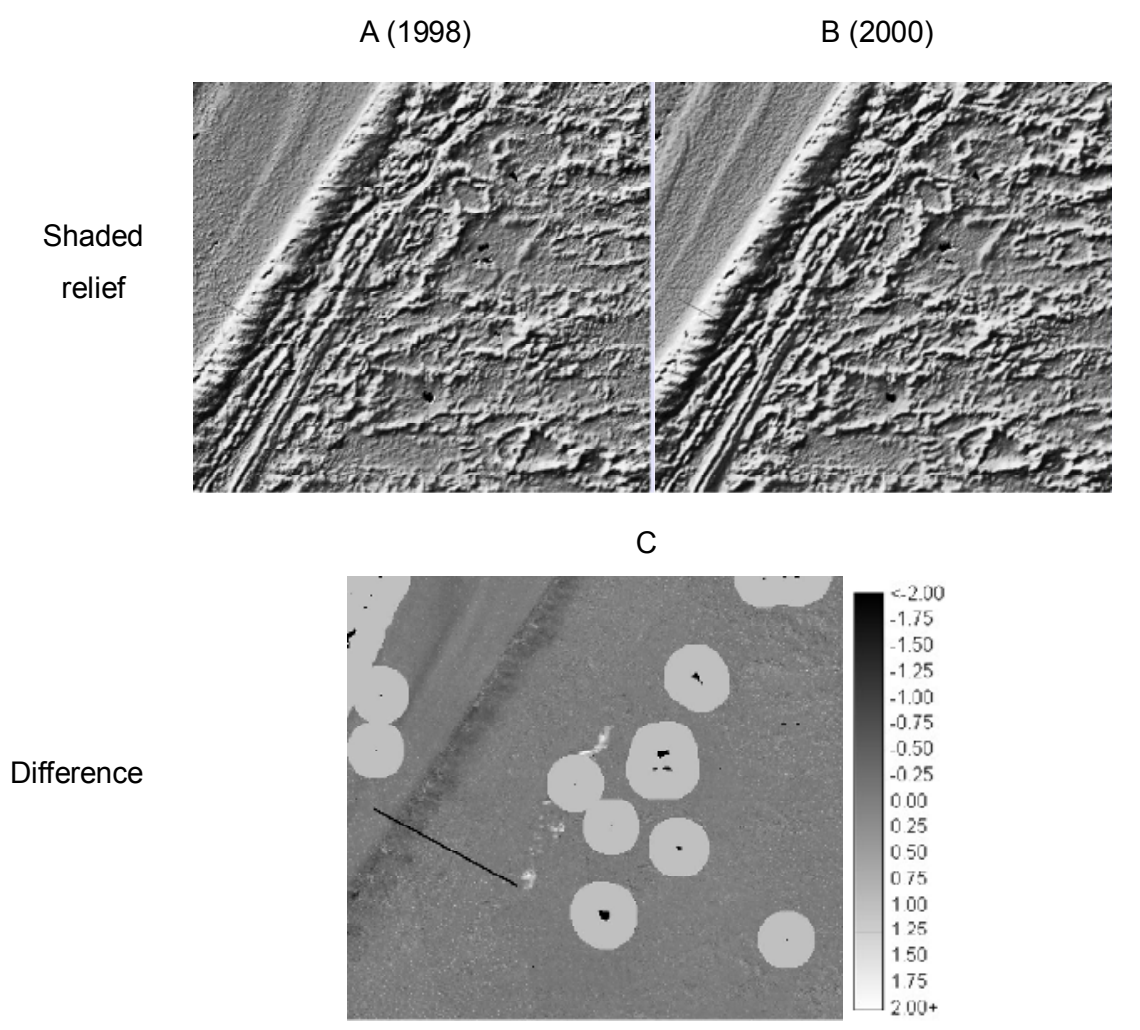

Notes: A and B show shaded relief maps of the dunefield and beach; areas shown as solid black recorded no return to the sensor due to surface wetness; $\mathrm{C}$ shows the difference in the two elevation datasets; the grey disks in $\mathrm{C}$ show those areas which are excluded from later analysis due to no LiDAR return from the focal points propagating into the multi-scale analysis; all maps show the same area of the dunes measuring 830 by 760 meters.

Figure 2. The LiDAR-derived elevation models (Reproduced here with permission from the Environment Agency).

Table 1. The Various Intersection Operations for Change in the Dune System (After Fisher et al. 2005)

\begin{tabular}{llllll}
\hline & & & $\mathrm{P}$ & $\mathrm{Q}$ \\
\hline Crestness & Gain & $\mu_{D C_{\text {gain }}}(x)$ & $\neg$ Crestness $_{\mathrm{t} 1}$ & $\cap$ & Crestness $_{\mathrm{t} 2}$ \\
& Loss & $\mu_{D C_{-} \text {loss }}(x)$ & Crestness $_{\mathrm{t} 1}$ & $\cap$ & $\neg$ Crestness $_{\mathrm{t} 2}$ \\
\multirow{3}{*}{ Troughness } & Gain & $\mu_{D T_{\_} \text {gain }}(x)$ & $\neg$ Troughness $_{\mathrm{t} 1}$ & $\cap$ & Troughness $_{\mathrm{t} 2}$ \\
& Loss & $\mu_{D T_{-} \text {loss }}(x)$ & Troughness ${ }_{\mathrm{t} 1}$ & $\cap$ & $\neg$ Troughness $\mathrm{t} 2^{2}$ \\
\hline
\end{tabular}

$$
\mu_{D C}(x)=1-\mu_{\neg D C}(x)
$$

In terms of logic, absence is determined by the negation of the relevant set, and in fuzzy sets negation is given by the usual formula (Klir and Yuan, 1995; Equation 5). It is necessary, however, to consider alternatives for the fuzzy intersection operation. As Fisher et al $(2005 ; 2006)$ point out, in a context of change detection, the result of the usual minimum operation is problematic because a location which has not changed still has a membership of the set of changed locations. This result is not acceptable, and so an alternative fuzzy intersection operator, the Bounded Difference, is chosen as being a more appropriate intersection method. The bounded difference between two sets, $\mathrm{P}$ and Q, is given in Equation 6:

$$
\mu_{P \cap Q}(x)=\max \left(0, \mu_{P}(x)+\mu_{Q}(x)-1\right)
$$

Therefore it is possible to determine the gain and the loss in dunes crests (DC) and dune troughs (DT) by substituting values for $\mathrm{P}$ and $\mathrm{Q}$ in Equation 6 from Table 1.

\subsection{Change in the Type-2 Fuzzy Sets}

The change in type-2 fuzzy sets is based on the change 
in type- 1 sets and use of the bounded difference. There are two pathways to change analysis, however:

(a) to determine the change for each instance of type-1 fuzzy sets generated by different values of curvature, and to then summarise those changes as the type-2 fuzzy set of changed vague locations by taking the summary values across the five type- 1 change sets; applying Equation 6 (for crests and troughs) to determine change analysis to each type-1 set and then summarising those using Equation 3 ( $a, b$ and $c$ );

(b) to work in the reverse order; applying Equation 3 (a, $\mathrm{b}$ and c) to summaries of the type- 1 sets of crestness and troughness, and then evaluate the change in those type- 2 sets using (Equation 6) for gain and loss.

Change is evaluated as the total area of fuzzy change which is given by the sum of all memberships of the fuzzy set in question within the study area ( $r$ rows by $c$ columns; Equation 7):

${ }^{F u z z y}{ }_{-} \operatorname{Area}_{\mu_{A}(x)}=\sum_{l=1}^{c} \sum_{k=1}^{r} \mu_{A}(x)_{l, k}$

\section{The Study Area and Implementation}

The empirical study used to support the theory developed above is in northwest England just south of Formby in Lancashire. The Ainsdale Sands is typical for British coastal sand dune fields. It is of considerable environmental importance as both a barrier to coastal flooding in a low lying area of coast and is a Site of Special Scientific Interest, which is home to a number of endangered species of British fauna including the natterjack toad and the red squirrel. The area is therefore of concern to the Environment Agency (EA) of England and Wales and as a result it has been the subject of ongoing research and monitoring (Brown, 2005) and the datasets used here have been part of other research on geographical information processing (Lucieer et al., 2005).

As part of that monitoring procedure the dunes have been the subject of repeated high resolution LiDAR survey with the creation of Digital Elevation Models (DEMs). Those collected in 1998 and 2000 are used here (Figure 2). The details of the pre-processing of these data are not relevant to this discussion, but they were made available as $2 \mathrm{~m}$ resolution DEMs registered to the Ordnance Survey National Grid covering a total area $2 \times 2 \mathrm{~km}$ for each date. LiDAR works by measuring the time taken for a beam of infrared light to travel from the sensor to the ground and back. Infrared light is totally absorbed by water, and so there is no reflection and hence no measurement from areas of very wet soil and water. Such areas can be seen in Figure 2C. The lack of a measurement in these areas will have an effect on the feature extraction procedures used in this research. The possible extent of this effect is indicated in Figure 2C, and excluded from subsequent analysis.

In the research reported here, a range of resolutions from $3 \times 3$ to $41 \times 41$ were chosen to identify morphometric classes from $4 \mathrm{~m}$ to $80 \mathrm{~m}$ in planimetric extent. This extent is chosen on the basis of an examination of profiles through the digital elevation model. The fuzzy memberships are, therefore, each based on $n=20$ (Equation 2) Boolean instances of landscape classification. A limited number ( $m=5$; Equations $3 \mathrm{a}, \mathrm{b}, \mathrm{c})$ of threshold values of $c$ are used, 0.1, 0.2, 0.3, 0.4 and 0.5. At each threshold, a different type-1 fuzzy membership was determined, and so each type-2 fuzzy set is based on 100 Boolean instances of morphometric classification.

The total area can be divided into three zones: the beach, and two areas of dunes, one wooded and one dominated by scrub. The wooded area is characterised by very erratic elevation readings due to the trees, and a patchwork of clearings which mean that the multiresolution analysis used here becomes unreliable, and therefore the work focuses on the scrubdune area (Figure 2).

Within the study zone, the dominant feature is the major foredune oriented from southwest to northeast, which reaches to more than $10 \mathrm{~m}$ above Ordnance Datum (OD), and is bounded to the south-east by a series of parallel ridges of what are presumed to be previous foredunes (Figure 2). Further inland a series of parabolic dunes fills the remainder of the area with extensive bare-sand blow-outs with high dune crests to the landward side, reaching occasionally as high as $20 \mathrm{~m}$ above OD at the eastern extremity. The dunes in this area are vegetated by a mixture of grasses, heathers and other small shrubs (Brown, 2005).

To execute the multi-resolution analysis we have used the method of Wood (1996a, b) as used by Fisher et al. (2004, 2005), where the land surface is modelled as a quadratic function using the central point and the outer points of an expanding window. A value of the elevation calculated from that surface is then recorded for the central point (Wood, 1996a). Morphometric analysis is then performed on the generalised surface. We used the Landserf software to execute these operations (Wood, 2006). Further processing and visualisation was completed with Clark Laboratory's Idrisi Kilimanjaro (Eastman, 2003).

Figure $2 \mathrm{C}$ shows the difference between the two elevation models. It seems that the foredune has received a considerable reduction in height, while some trough areas have been subject to accumulation. In addition, a secondary foredune (seaward of the main dune crest) seems to have developed between 1998 and 2000. Overall the dune system would appear to be little changed, with some filling of troughs and levelling of dunes. The possibility of error in the elevations cannot be excluded. The DEMs were produced to the highest standards, however, and have passed quality assurance procedures by both the Environment Agency and the data producers. Therefore, for the present analysis we take them both to be correct.

\section{Analysis of Type-1 Fuzzy Landforms}

\subsection{Type-1 Fuzzy Set Membership}

The distribution of crestness and troughness is shown in Figure 3. The columns in the figure show the crestness and troughness at the different dates, while the rows show results 


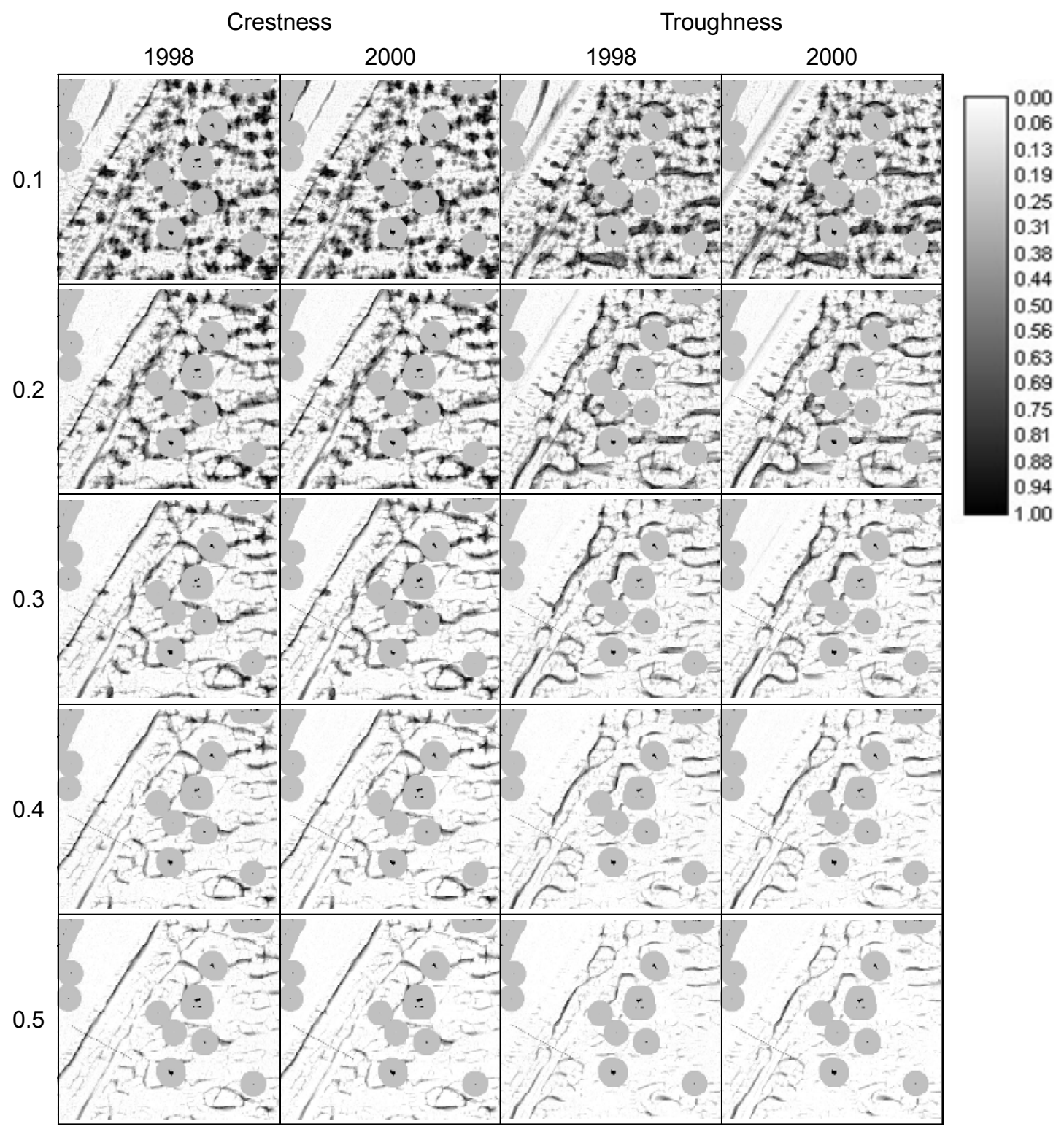

Figure 3. Crestness and troughness for each curvature parameterisation in 1998 and 2000.

from the 5 different parameterisations of curvature. The most obvious feature is that the larger values of curvature allow a more restricted interpretation of what should be distinguished as either crest or trough. When $c=0.1$ quite a large proportion of the study area is classed to a degree as crest or trough, but as the value of $c$ increases the degree of crestness or troughness generally decreases, although in locations with the highest values of fuzzy membership the degree remains much the same for different values of curvature.

The principal feature in all the crestness maps, especially those with larger values of curvature is the foredune. Parallel to this dune crest is a secondary, landward crest which becomes increasingly obvious as the value of curvature increases. Other minor dunes parallel to the foredune are also appa- rent forming dashed lines (in effect) between these two major dunes. The generally larger values of fuzzy membership associated with the smaller values of curvature mean that some other coherent areas of larger values of crestness are also present. Further inland, the crests become more east-west trending almost forming closed loops in some cases. This is the area of parabolic dunes typical of coast dunefields (Pethick, 1984).

In the crestness maps (Figure 3) for both years, when $c=$ 0.1 , a pronounced zone of higher values of crestness is apparent in the beach area. Beach ridges are characteristic of the shore, are caused by tidal activity and vary with tides. The ridge could mark the high tide line or the strand line of the highest tides in the lunar cycle (Pethick, 1984). 
Two further columns in Figure 3 show maps of troughness. Much the same observations can be made as for crestness in terms of the more restricted extent of troughness with increasing values of curvature. A series of parallel areas of slightly elevated values of troughness run towards the beach from the foredune. Moving inland (to the east) a discontinous but prominent zone of large memberships of troughness is apparent running parallel and just to landward to the foredune. The zone is not continuous, however, like the foredune, but includes breaks and almost a horseshoe shape (possibly relating to a past break in the foredune). Indeed, at one point a prominent zone of troughness runs through the foredune at both dates (although the degree of troughness is definitely reduced in the 2000 analysis). Further inland, the parabolic dunes dominate the landscape, and, like the crests, the zones of troughness are either short linear features tending east-west, or they are approximately horseshoe shaped. Most of the general patterns commented on here are detectable in any of the curvature parameterisations of crestness or troughness, to some degree.

Finally, Table 2 presents the percentage of the study area (as the fuzzy area) which is occupied by the fuzzy dune crests and dune troughs in each year. Again it is possible to see the reduction in area of the fuzzy dunes with increasing curvature. The area of dune troughness is always a little less than the area of dune crestness.

Table 2. The Percent of the Study Area in the Type-1 Fuzzy Class Dune Crest and Dune Trough in Each Year for the Different Parameterisations of Curvature

\begin{tabular}{lllll}
\hline & Crestness & \multicolumn{3}{l}{ Troughness } \\
\hline & 1998 & 2000 & 1998 & 2000 \\
0.1 & 26.41 & 26.01 & 25.20 & 24.66 \\
0.2 & 18.25 & 17.75 & 16.14 & 15.77 \\
0.3 & 11.98 & 11.51 & 9.65 & 9.33 \\
0.4 & 7.82 & 7.43 & 5.79 & 5.52 \\
0.5 & 5.22 & 4.86 & 3.50 & 3.27 \\
\hline
\end{tabular}

\subsection{Change Analysis of Type-1 Sets}

Applying the logic of change discussed in section 3 to the individual curvature instances of type-1 fuzzy sets of crestness and troughness, gives rise to maps of fuzzy change. These are presented as Figures 4 and 5. Relatively speaking the amount of change is never large (note different legends between Figures 3, 4 and 5), but some change occurs in all curvatures in both crestness and troughness.

The amount of change in crestness is to the extreme northeast of the study area in the vicinity of an area of no return of signal and is likely to be related to edge effects of this area. The second most prominent change in both gain and loss of crestness is in the crest area to seaward of the foredune in the analysis when $c=0.1$, noted in section 5.1 . The effect is most likely to be related to the very dynamic beach area, and possibly to the state of the tide within the lunar cycle on the dif- ferent dates of LiDAR flights. The next most obvious features are the linear zones of crestness gain and loss associated with the foredune. Some further zones of irregular shape characterised by larger memberships of both gain and loss are noticeable inland of this. Further areas of change (both gain and loss are noticeable as coherent areas (not isolated small patches) arranged longitudinally running east to west, parallel to the crests of the parabolic dunes.

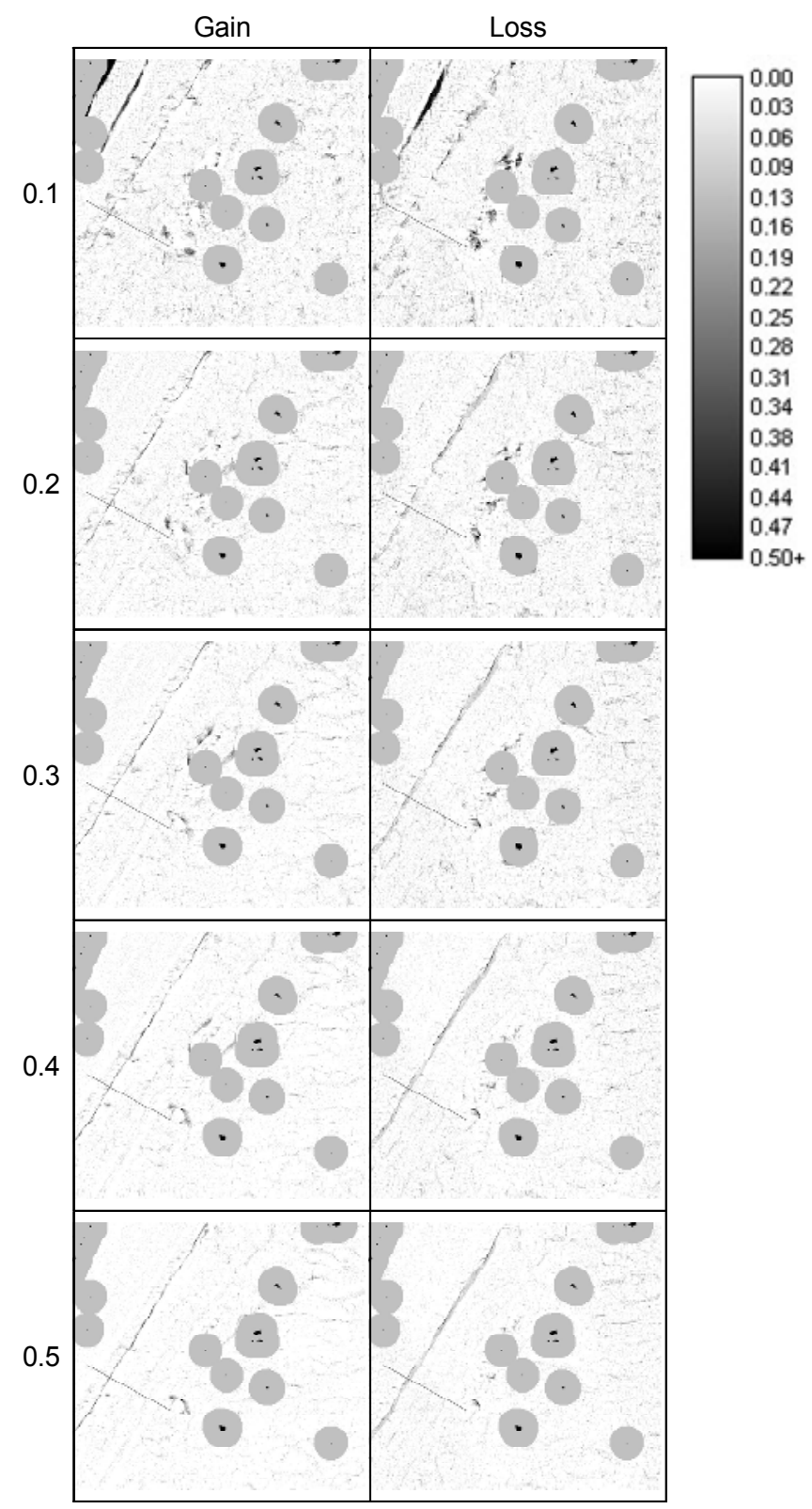

Figure 4. Change of Crestness for each curvature parameterization.

The change in troughness is somewhat similar. The tidal changes are expressed as a zone of loss of troughness, and there is a zone of large membership of loss of troughness, when $c=0.1$, associated with the foredune in the same broad 
area as that where crest gain was noted. This is due to smoothing of the seaward side of the foredune. The only other zone of large memberships is in the area of irregular changes of crestness immediately landward of the foredune.

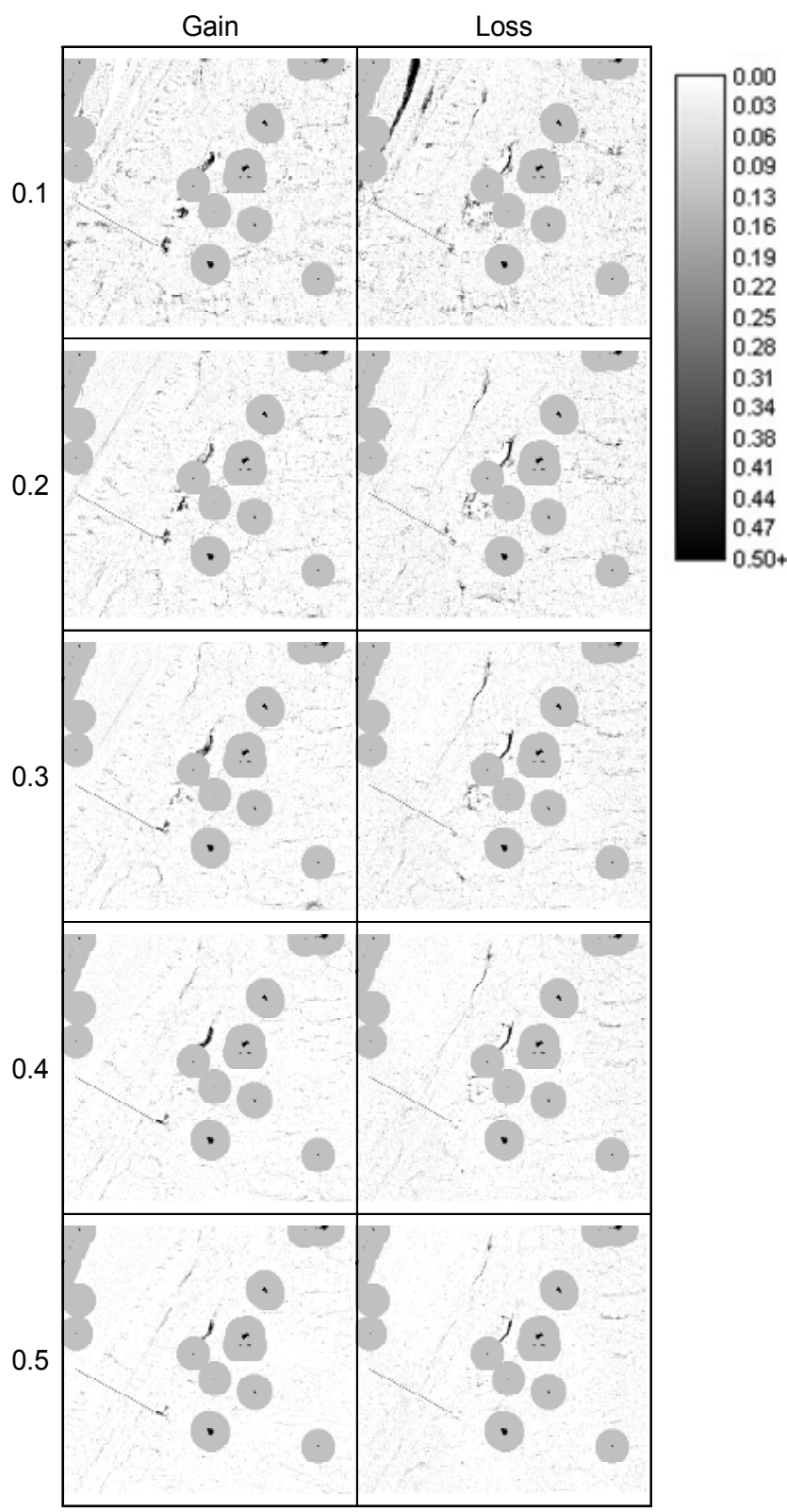

Figure 5. Change of troughness for each curvature parameterization.

From the analysis of change in type-1 fuzzy sets for any curvature, the overall picture of change shows some seaward gain and landward loss in the foredune crest as well as development of a new trough on the seaward side of the foredune. Otherwise there is a picture of minor re-arrangement of sand (leading to changes in crestness and troughness) in the parabolic dunes, with an area of larger re-arrangement of the crest and loss of trough immediately landward of the foredunes.
The minor amount of change in the dunes is evidenced also in the percent of fuzzy areal change reported in Table 3. All figures are low (but as is reflected in the maps) the values associated with larger values of curvature are smaller. Overall there is a slightly larger loss than gain in both dune-elements given all parameterisations of curvature. This imbalance in gain and loss is reflected in the reduction in the area of both dune and trough which can be observed in the area of the fuzzy crest and fuzzy trough between 1998 and 2000 (Table 2).

Table 3. The Percent of the Study Area in the Type-1 Fuzzy Change Class Gain and Loss of Dune Crest qnd Dune Trough for the Different Parameterisations of Curvature

\begin{tabular}{lllll}
\hline & Crest & \multicolumn{3}{c}{ Trough } \\
\hline & Gain & Loss & Gain & Loss \\
0.1 & 2.235 & 2.636 & 2.174 & 2.713 \\
0.2 & 1.449 & 1.955 & 1.541 & 1.904 \\
0.3 & 1.108 & 1.578 & 1.124 & 1.447 \\
0.4 & 0.850 & 1.243 & 0.797 & 1.071 \\
0.5 & 0.639 & 1.003 & 0.552 & 0.773 \\
\hline
\end{tabular}

\subsection{Summary}

The change analysis of type-1 fuzzy sets of crestness and troughness show a consistent picture of the slight events in the dune area. Changes are occurring, but none are dramatic, and overall, the morphological components are reducing in their spatial extent. This is likely to relate to a smoothing of the field (filling of the troughs and erosion of the crests) in the two year period. If this persists it may be a concern for the Environment Agency, because the wind- and wave-break effect of the dunes is lowered with this smoothing. The exact effects are hard to quantify. It is reassuring, however, that losses in morphological components are matched by gains (only a little less in spatial extent than the losses) elsewhere in those same components.

If only a type- 1 analysis were being performed any of the 5 different results could be reported as a correct representation of the fuzzy change of the dunes. There might only have been an arbitrary reason for choosing the curvature value (Fisher et al., 2005), but the result would be treated as a definite statement. The inclusion of the different results here is a result of wishing to extent to a type-2 analysis.

\section{Analysis of Type-2 Fuzzy Landforms}

\subsection{Type-2 Fuzzy Set Membership}

As noted in Section 3.2, the type-2 fuzzy membership function is generated by summarising the distribution of the five different type-1 fuzzy memberships. The summary is in the form of at least two different values, the minimum and maximum membership (Equations $3 \mathrm{a}$ and $3 \mathrm{~b}$ ), with the mean (Equation 3c) defining a triangular type-2 function for the boundary condition of areas of crestness and troughness, which might be interpreted as generous, typical and core inter- 
pretations of crestness and troughness.

Maps of these type-2 crestness and troughness parameters are shown in Figure 6. For the minimum and maximum values the general patterns are the same as in the 0.5 and 0.1 curvature maps shown in Figure 3. The details are not however the same, but strongly related (correlation coefficient $=0.96$ ). It is not necessarily the case that the minimum value at a location is the value from the 0.5 curvature analysis; rather it is the least membership in any of the different curvature values. Thus it is occasionally the case that the smallest membership value for a location is not in the 0.5 curvature mapping, and similarly, the largest value at a location is not the 0.1 mapping.

Table 4. The Percent of the Study Area in the Type-2 Fuzzy Change Class Gain and Loss of Dune Crest and Dune Trough Based on the Multiple Parameterisations of Curvature

\begin{tabular}{lllll}
\hline & Crest & \multicolumn{3}{c}{ Trough } \\
\hline & 1998 & 2000 & 1998 & 2000 \\
Min (core) & 4.77 & 4.40 & 3.13 & 2.91 \\
Mean (typical) & 13.94 & 13.51 & 12.05 & 11.71 \\
Max (generous) & 28.07 & 27.65 & 26.85 & 26.27 \\
\hline
\end{tabular}

The difference between the type- 2 and the type- 1 fuzzy sets from separate curvature analyses is also apparent when Tables 2 and 4 are compared. The fuzzy areas of the type- 2 set maxima are all larger than the percent of the study area in the 0.1 curvature areas and the minima are all smaller than the 0.5 curvature values. Thus the minimum of the type- 2 set should be seen as the most restricted estimate of the extent of crestness and troughness (the core areas) in the dune area, just as the maximum is the largest extent (most generous). The mean might therefore be interpreted as a more typical interpretation of the areas of the crest or trough than either of the others.

Between them, the minimum, mean and maximum define the triangular membership of the boundary condition of the type-2 fuzzy sets of crestness and troughness; the range and distribution of possible values of the membership function exemplified by the mappings of the 5 curvature values.

\subsection{Change Analysis}

In Section 3.5 two different approaches to the analysis of change in type-2 fuzzy sets were introduced. Here they are discussed in separate subsections.

\subsubsection{Summarising Type-1 Fuzzy Change}

The first approach is to take the summary parameters of the triangular fuzzy function from the memberships of the type- 1 change sets for multiple values of curvature (Figures 4 and 5). These are presented in Figures 7 and 8 for crestness and troughness, respectively, and the areas are summarised in Table 5.

Perhaps not surprisingly the patterns are much as in the type- 1 analysis, but as observed in section 6.1 the detailed values are different. The percent of the study area which has the maximum value of any change is larger than the 0.1 curvature values by more than half as much again, and the minimum is smaller than the 0.5 by as much as one quarter (compare Tables 3 and 5). Unlike the maps of type-1 change in crestness where both gain and loss of the foredune is apparent in all maps as a linear feature cutting across the whole study area, in the minimum membership of type- 2 change in crestness images (Figure 7), the change in the foredune is intermittent to say the best and hardly visible in the loss map. In the mean gain map it is hard to seem, but it is more apparent in the loss image. It is only clear in the maximum membership mapping.

Table 5. The Percent of the Study Area in the Type-2 Fuzzy Change Gain and Loss of Dune Crest and Dune Trough Based on the Multiple Instances of Curvature

\begin{tabular}{lllll}
\hline & Crest & \multicolumn{3}{c}{ Trough } \\
\hline & Gain & Loss & Gain & Loss \\
Min & 0.159 & 0.349 & 0.152 & 0.229 \\
Mean & 1.256 & 1.683 & 1.238 & 1.582 \\
Max & 3.588 & 4.301 & 3.479 & 4.308 \\
\hline
\end{tabular}

\subsubsection{Change in Type-2 Sets}

The alternative method of analysis is to apply the change logic (Equation 6) to the parameters of the type- 2 sets of crestness and troughness (Figure 6). The results of this analysis are presented in Figures 9 and 10.

An examination of individual locations reveals unexpected results. At many locations the membership of change of the type-2 minimum membership is actually larger than membership of change of the type-2 mean or even the maximum membership. This issue can be observed most clearly in a set of profiles through these maps of change of the type-2 fuzzy set memberships (Figure 11). There are many locations in all profiles where the largest fuzzy membership values are actually of the change in the mean or minimum rather than of the maximum.

One view of this result is that, at some locations, the change in the type- 2 set has created a concave set, rather than a convex one which is axiomatic for fuzzy sets (Zadeh, 1965; Klir and Yuan, 1995; Kruse et al., 1994). In still more extreme instances the order of the membership values of maximum, mean and minimum is reversed, and so it seems that the set is actually inverted. This observation is, however, completely reasonable and logical; there is no reason at all that the change in the minimum values of the type- 2 fuzzy sets of the crest and trough should necessarily be the smallest type- 2 change set at all locations. Instead of considering these results as describing the triangular membership function at a point, they can be more usefully viewed as further instances of the change of the fuzzy dunes, just as the different values of curvature were treated, and so summarised by taking the minimum and maximum memberships at any location. Here, only the minimum and maximum is reported since being derived from three 


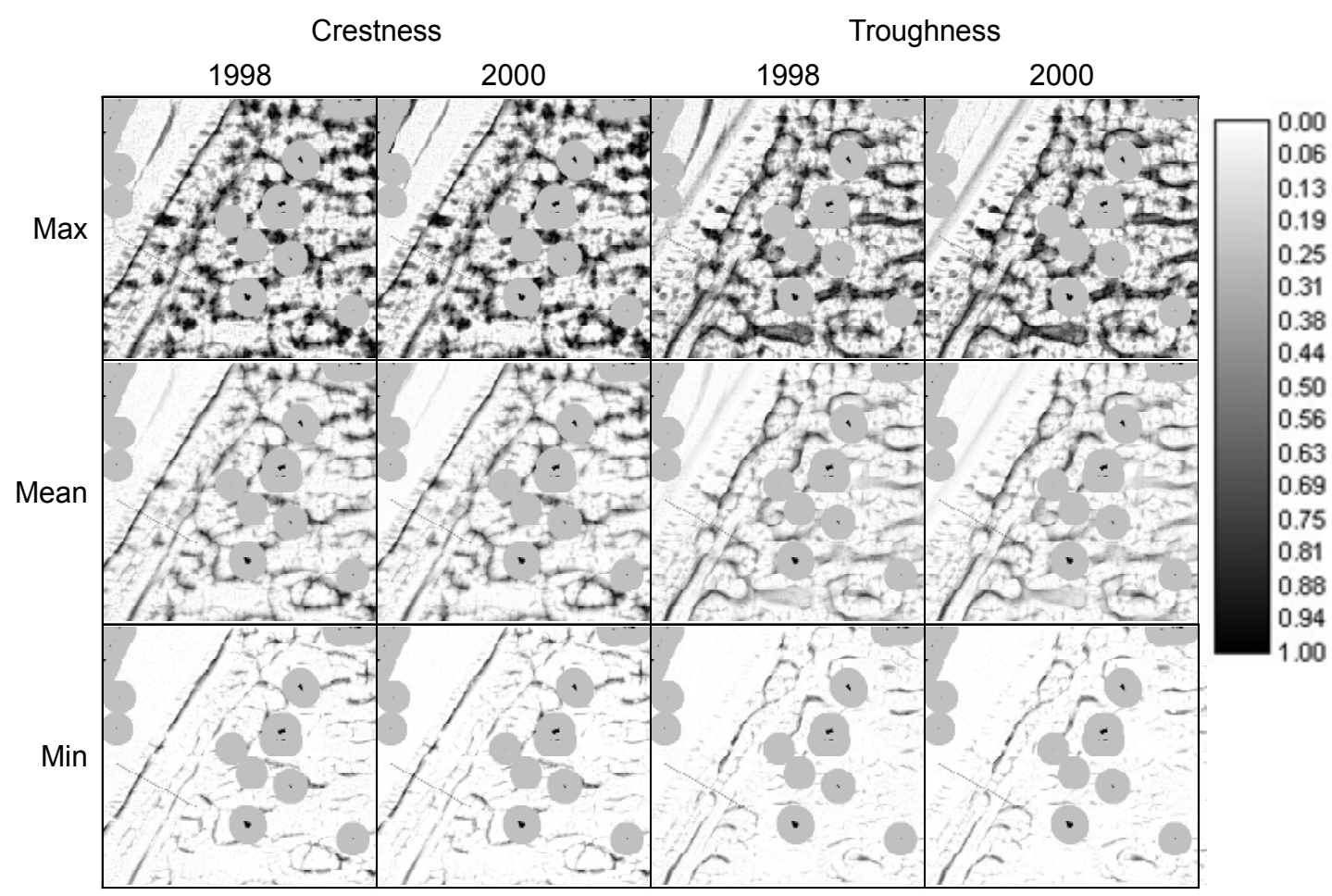

Figure 6. Type- 2 set of crestness and troughness, being summaries of the fuzzy memberships shown in Figure 5.

values it was considered that the mean would be relatively meaningless. The fuzzy areas in the minimum and maximum values of the changes of the type- 2 sets are smaller and larger, respectively, than any previous change analysis (compare Tables 3 and 5 with Table 6).

Table 6. The Percent of the Study Area in the Change of Type-2 Fuzzy Classes of Dune Crest and Dune Trough, Based on Summarising Change of the Type-2 Sets

\begin{tabular}{lllll}
\hline & Crest & \multicolumn{3}{c}{ Trough } \\
\hline \multirow{3}{*}{ Min } & Gain & Loss & Gain & Loss \\
Max & 0.240 & 0.464 & 0.228 & 0.323 \\
\hline
\end{tabular}

\section{Conclusions}

The treatment of environmental phenomena with fuzzy sets has largely been done in two ways (Robinson, 1988): by clustering and related numerical classification methods in the Similarity Relation Model, and by user specification in the Semantic Import Model. This paper uses multiple instances in an example of the approach which is referred to by Fisher (2000b) as the Experimental Model, and is similar to Kulik's (2003) supervaluation approach. The approach uses multiple instances (or precisifications) of an algorithm or algorithms which may be expected to produce different results. In the current study the difference is created by varying the scale (or resolution) of analysis (following Fisher et al., 2004, 2005), in what is an inherently geographical method for populating type-1 fuzzy sets. The curvature is then varied to generate multiple instances of the type- 1 sets which can be summarised to yield type-2 sets.

Change analysis of fuzzy sets of vague landscape phenomena is not widespread, because, at least in part, the appropriate logic of change analysis has only recently been developed. Some studies have been done in remote sensing, but these have tended to avoid specifying any logical analysis, unless on objects (Tang et al., 2005). This paper is intended to contribute to that literature. Following Deer (1998) and Fisher et al. $(2005,2006)$, the logic of fuzzy change analysis is articulated and the results of such change analysis explored.

Over the time period for which data is available, little change has occurred in the study area, and that is typical of the coastal sand dunes in Britain. Change in this environment occurs slowly, due to the wind blowing sand from the beach onto the dunes, and rainfall causing the erosion of that sand. Vegetation of the dunes, as has occurred in the Ainsdale sands, partially stabilises the dunes. Even in protected areas pressure from human walkers can cause degradation, but the dunes examined here are far enough from car parks and hotels that only the more determined walkers will affect the dunes. Catastrophic events such as extreme storms can cause dramatic changes, but no such events occurred in this area between 1998 and 2000. Therefore the small scale or slight changes apparent in the fuzzy analysis are therefore consistent with expectations. 


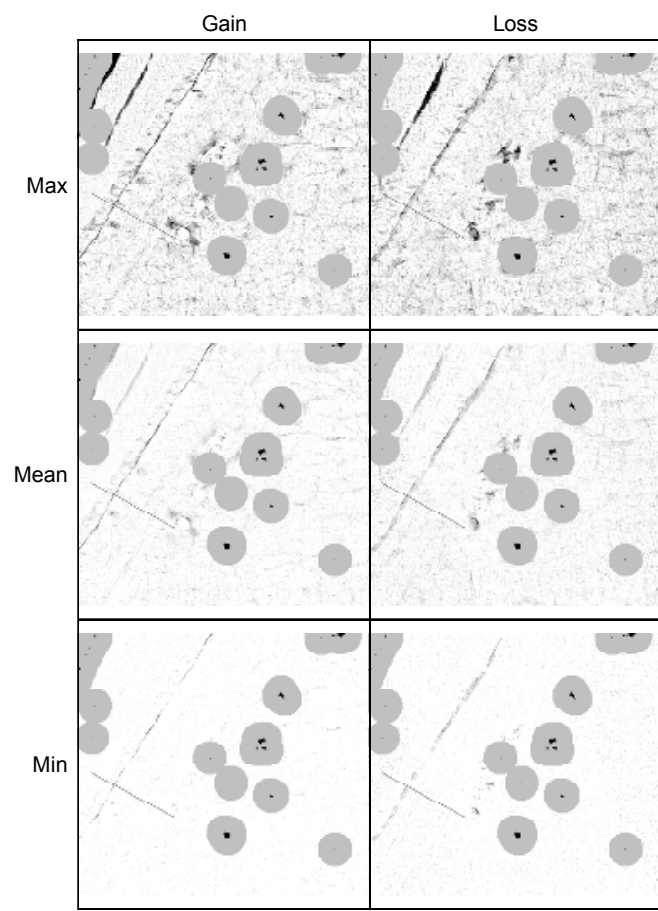

Figure 7. Type-2 set of change of Crestness summarizing the multiple curvature change values.

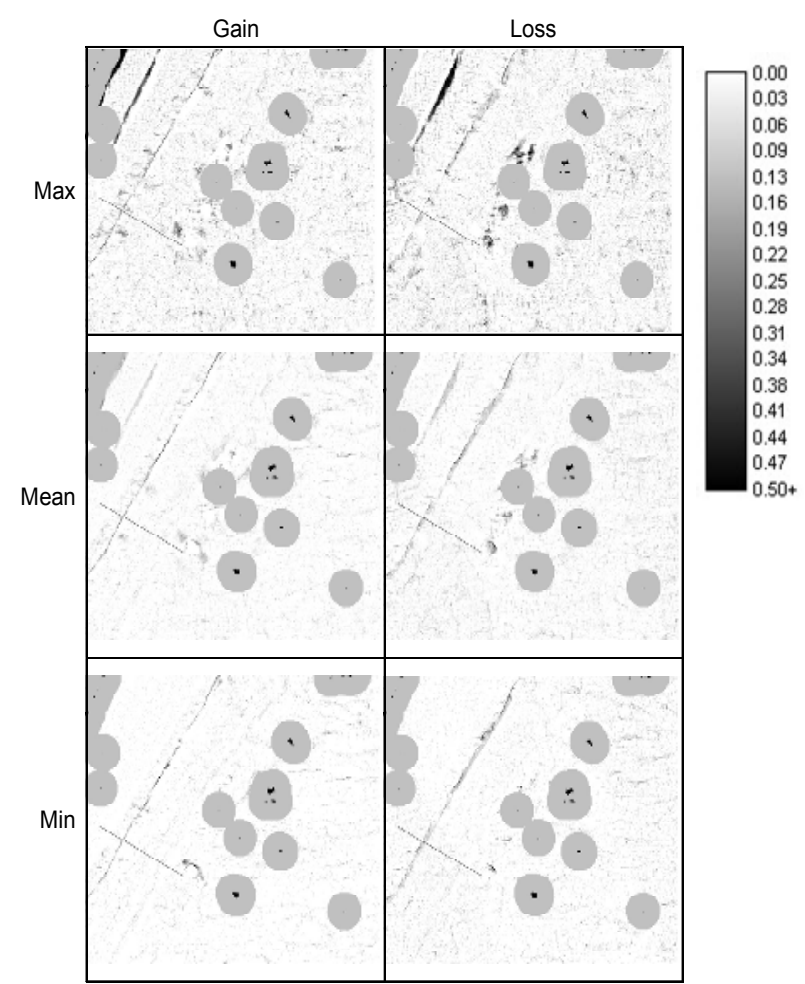

Figure 9. Change of the summaries of the type-2 set Crestness shown as profiles along the line indicated to the lower left of each image in Figure 11.

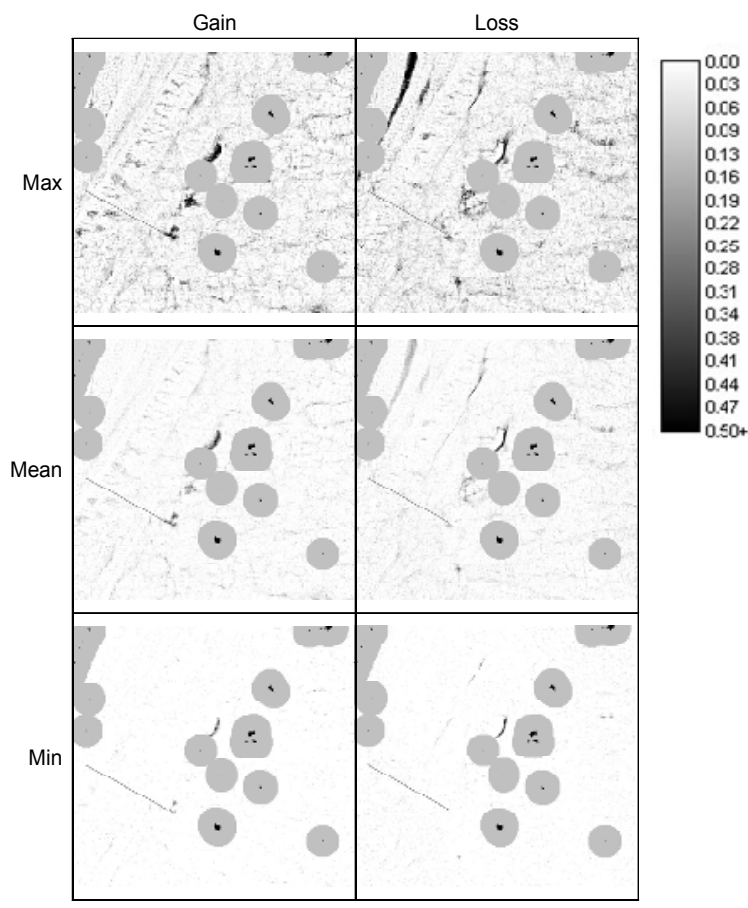

Figure 8. Type-2 set of change of troughness summarizing the multiple curvature change values.

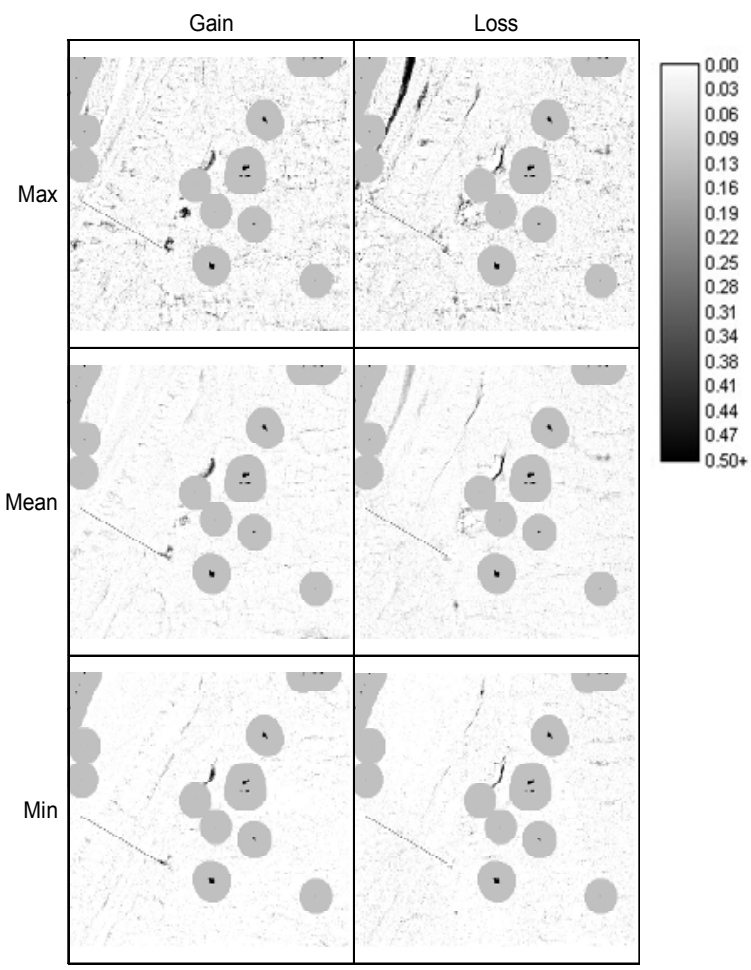

Figure 10. Change of the summaries of the type- 2 set Troughness shown as profiles along the line indicated to the lower left of each image in Figure 11. 

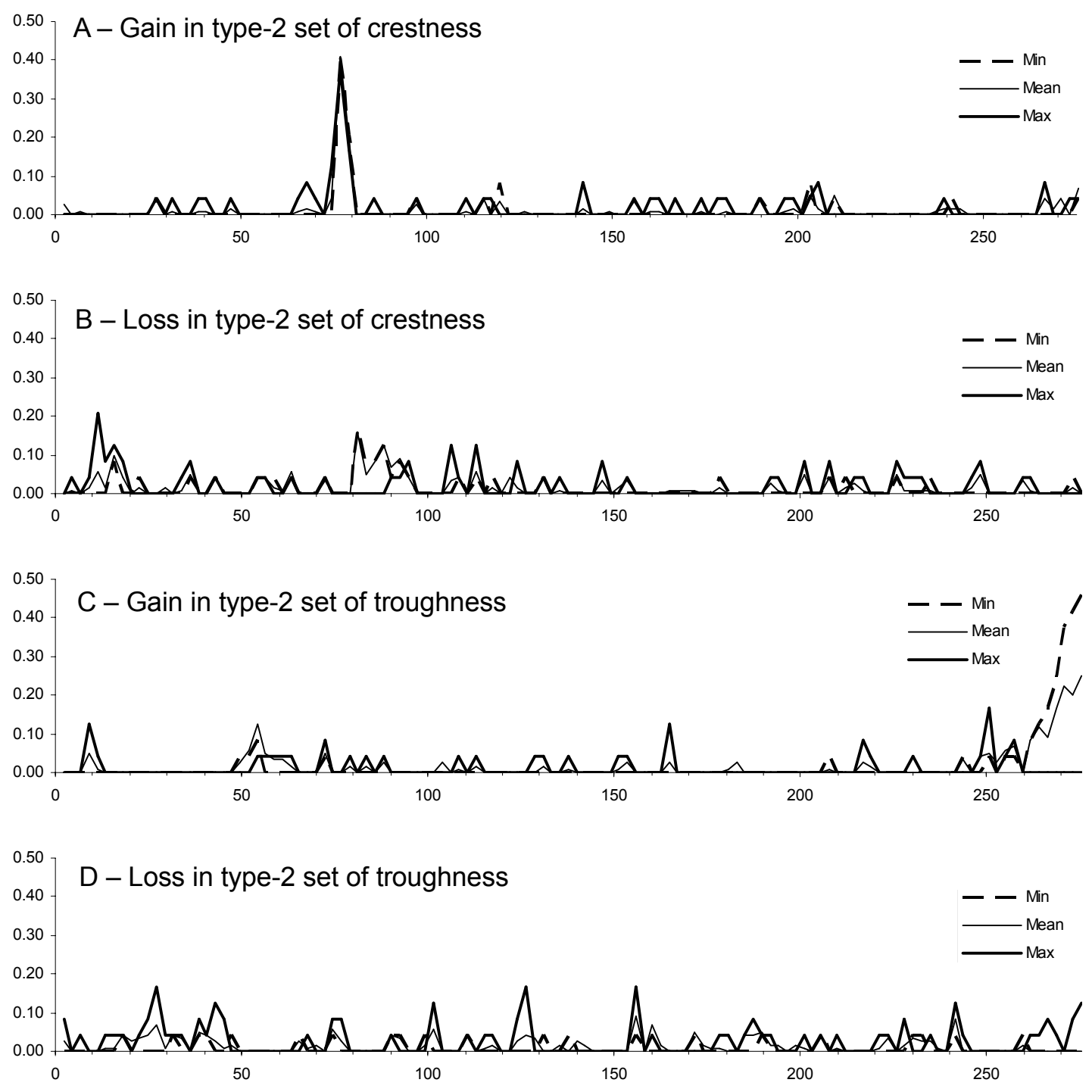

Figure 11. Profiles through the change in type-2 sets of crestness by A) gain and B) loss, and troughness by C) gain and D) loss (the position of the profile is shown by a straight line in Figure $2 \mathrm{C}$, and all other map views).

The analysis of type-2 fuzzy sets and of higher order vagueness in general is also not widespread in the environmental informatics literature. In this paper, an empirical study of the properties of type- 2 sets is presented. By varying the curvature threshold in the allocation of locations to the channels and ridges, it is possible to generate multiple instances of type-1 fuzzy sets of crestness and troughness, and to then use the variation in those sets to determine the distribution of the type- 2 sets (Table 5). This gives the most restricted parameters for the type- 2 fuzzy sets, and the estimates of the fuzzy areal extent of change of the type- 2 sets of crestness and troughness show larger and smaller areas of change (Table 6). Indeed the minimum estimates are lowered and the maximum estimates raised in the type- 2 analysis, and this difference is extended in summarising the change in the type- 2 sets of troughness and crestness.
In this paper the method uses instances of type- 1 sets and so it is possible to parameterise change in all type- 1 sets and summarise those as type- 2 sets, which yields the most restricted version of the type- 2 sets. If the Semantic Import Model were to be used to populate the type- 1 and type-2 fuzzy sets from the expert's opinion of the range of values for the membership function, as is much more common, then only the second type of analysis presented here will be possible, performing change analysis on the parameters of the type- 2 sets. Therefore it seems reasonable to conclude that the range of possible change which might be detected would be greater than seems to actually be the case. This is a warning for those working with type-2 fuzzy sets where the Semantic Import Model is usual; the consequence of logical analysis of the type-2 sets may over estimate the range of possible membership values. 
In conclusion, the memberships of type-1 fuzzy sets have been estimated from instances of differently parameterised morphometric landform classifications. From these fuzzy morphometric elements of sand dunes have been distinguished and memberships determined. Changes in these type-1 sets have been explored yielding varied but small changes in the morphometric elements of the dunes in the Ainsdale Sands dunefield. Type-2 fuzzy sets have also been estimated for both the morphometric elements and for the change in those elements. These type- 2 change sets show more varied possible change than the type- 1 sets which may be a warning for others applying logical analysis to type- 2 fuzzy sets. The analysis of multiple instances of type-1 fuzzy sets and of type-2 fuzzy sets are equally useful. Both yield ranges of values for possible events for vague phenomena, supporting the basic contention that these phenomena are themselves vague, or at least that as an output from analysis they are vague.

Acknowledgments. We would like to thank Al Duncan and Kyle Brown of the Environment Agency for their cooperation and supplying the data used in this paper. The comments of two anonymous reviewers are gratefully acknowledged.

\section{References}

Bennett, B. (2001). What is a forest? On the vagueness of certain geographic concepts. Topoi., 20, 189-201.

Brown, K. (2005). Per-pixel uncertainty for change detection using airborne sensor data, in P.M. Atkinson, G.M. Foody, S.E. Darby and F. Wu, Geodynamics, pp. 103-118.

Brown, W., Groves, D. and Gedeon, T. (2003). Use of fuzzy membership input layers to combine subjective geological knowledge and empirical data in a neural network method for mineral-potential mapping. Nat. Resour. Res., 13(3), 183-200.

Burrough, P.A. (1989). Fuzzy mathematical methods for soil survey and land evaluation. J. Soil Sci., 40, 477-492.

Burrough, P.A., van Gaans, P.F.M. and MacMillan, R.A. (2000). High-resolution landform classification using fuzzy k-means. Fuzzy Sets Syst., 113, 37-52.

Campbell, J.B. (1977). Variation of selected properties across a soil boundary. Soil Sci. Soc. Am. J., 41, 578-582.

Cheng, T. and Molenaar, M. (1999). Diachronic analysis of fuzzy objects. GeoInformatica, 3(4), 337-356.

Deer, P. (1998). Digital Change Detection in Remotely Sensed Imagery Using Fuzzy Set Theory, Ph.D. Dissertation, University of Adelaide, Australia.

Du, G. and Zhu, Z. (2006). Modelling spatial vagueness based on type-2 fuzzy sets. J. Zhejiang Univ., Sci. A, 7(2), 250-256.

Eastman, J.R. (2003). Idrisi Kilimanjaro: Guide to GIS and Image Processing, Clark Univeristy, Worcester.

Elith, J., Burgman, M.A. and Regan, H.M. (2002). Mapping epistemic uncertainties and vague concepts in predictions of species distribution. Ecol. model., 157, 313-329.

Evans, I.S. (1979). An Integrated System of Terrain Analysis and Slope Mapping, final report on grant DA-ERO-591-73-G0040, University of Durham.

Evans, I.S. (1980). An integrated system of terrain analysis and slope mapping. Zeitschrift fur Geomorphologie, Suppl-Bd, 36, 274 295

Fine, K. (1975). Vagueness, truth and logic. Synthese, 30, 265-300.

Fisher, P.F. (2000a). Sorites paradox and vague geographies. Fuzzy
Sets Syst., 113(1), 7-18.

Fisher, P.F. (2000b). Fuzzy modelling, in S. Openshaw, R. Abrahart and T. Harris, Geocomputing, Taylor \& Francis, pp. 161-186.

Fisher, P.F. and Wood, J. (1998). What is a mountain? or the englishman who went up a boolean geographical concept and realised it was fuzzy. Geogr., 83, 247-256.

Fisher, P.F., Wood, J. and Cheng, T. (2004). Where is Helvellyn? multiscale morphometry and the mountains of the English Lake District. Trans. Inst. Br. Geogr., 29, 106-128.

Fisher, P.F., Wood, J. and Cheng, T. (2005). Fuzziness and ambiguity in multi-scale analysis of landscape morphometry, in F. Petry, V. Robinson and M. Cobb, Fuzzy Modeling with Spatial Information for Geographic Problems, Springer, pp. 209-232.

Fisher, P.F., Arnot, C., Wadsworth, R. and Wellens, J. (2006). Detecting change in vague interpretations of landscapes. Ecol. Inf., 1(2), 163-178

Fisher, P.F., Cheng, T. and Wood, J. Higher order vagueness in geographical information: Empirical geographical population of Type $\mathrm{n}$ fuzzy sets. GeoInformatica (in press).

Foody, G.M. (1992). A fuzzy sets approach to the representation of vegetation continua from remotely sensed data: An example from lowland heath. Photogramm. Eng. Remote Sensing, 58, 221-225.

Foody, G.M. (1996). Approaches to the production and evaluation of fuzzy land cover classification from remotely-sensed data. Int. $J$. Remote Sensing, 17, 1317-1340.

Irvin, B.J., Ventura, S.J. and Slater, B.K. (1997). Fuzzy and isodata classification of landform elements from digital terrain data in Pleasant Valley, Wisconsin. Geoderma, 77(2-4), 137-154.

John, R.I. (1998). Type-2 Fuzzy sets: An appraisal of theory and applications. Int. J. Uncertainty, Fuzziness Knowledge-based Syst., 6 , 563-576.

Keefe, R. and Smith, P. (Eds.) (1996). Vagueness: A Reader, MIT Press.

Klir, G.J. and Yuan, B. (1995). Fuzzy Sets and Fuzzy Logic: Theory and Applications, Prentice-Hall.

Kruse, R., Gebhardt, J. and Klawonn, F. (1994). Foundations of Fuzzy Systems, John Wiley \& Son.

Kulik, L. (2003). Spatial vagueness and second order vagueness. Spatial Cognition Comput., 3, 157-183.

Lagacherie, P., Caxemier, D.R., van Gaans, P.F.M. and Burrough, P.A. (1997). Fuzzy k-means clustering of fields in an elementary catchment and extrapolation to a larger area. Geoderma, 77, 197216.

Luo, X. and Dimitrakopoulos, R. (2003). Data-driven fuzzy analysis in quantitative mineral resource assessment. Comput. Geosci., 29, 3-13.

Lucieer, A., Stein, A. and Fisher, P. (2005). Multivariate texture segmentation of high-resolution remotely sensed imagery for identification of fuzzy objects. Int. J. Remote Sensing, 26(14), 2911-2915.

MacMillan, R.A., Pettapiece, W.W., Nolan, S.C. and Goddard, T.W. (2000). A generic procedure for automatically segmenting landforms into oandform elements using DEMs, heuristic rules and fuzzy logic. Fuzzy Sets Syst., 113, 81-109.

Mendel, J.M. (2001). Uncertain Rule-Based Fuzzy Logic Systems: Introduction and New Directions, Prentice-Hall.

Mendel, J.M. and John, R.I. (2002). Type-2 fuzzy sets made simple. IEEE Trans. Fuzzy Syst., 10, 117-127.

Mizumuto, M. and Tanka, K. (1976). Some properties of fuzzy sets of type-2. Inf. Control., 31, 312-340.

Moraczewski, I.R. (1993a). Fuzzy logic for phytosociology 1: Syntaxa as vague concepts. Vegetatio, 106, 1-11.

Moraczewski, I.R. (1993b). Fuzzy logic for phytosociology 2: Gene- 
ralization and prediction. Vegetatio, 106, 13-20.

Pethick, J. (1984). An Introduction to Coastal Geomorphology, Edward Arnold.

Peucker, T.K. and Douglas, D.H. (1974). Detection of surface specific points by local parallel processing of discrete terrain elevation data. Comput. Graphics Image Process., 4, 375-387.

Robinson, V.B. (1988). Some implications of fuzzy set theory applied to geographic databases. Comput., Environ. Urban Syst., 12, 89-98.

Robinson, V.B. and Graniero, P.A. (2005). Spatially explicit individual-based ecological modeling with mobile fuzzy agents, in F. Petry, V. Robinson and M. Cobb, Fuzzy Modeling with Spatial Information for Geographic Problems, Springer, pp. 299-334.

Ross, T.J. (2004). Fuzzy Logic with Engineering Applications, John Wiley \& Sons.

Sainsbury, R.M. (1989). What is a vague object? Anal., 49, 99-103.

Sainsbury, R.M. (1991). Is there higher order vagueness?, The Philos. Q., 41, 167-182.

Sainsbury, R.M. (1995). Paradoxes, 2nd Edition, Cambridge University Press.

Sorensen, R.A. (1985). An argument for the vagueness of the 'vague'. Anal., 45, 134-137.

Tang, X.M., Kainz, W. and Fang, Y. (2005). Reasoning about changes of land cover with fuzzy settings. Int. J. Remote Sensing, 26,
3025-3046.

Usery, E.L. (1996). A conceptual framework and fuzzy set implementation for geographic features, in P.A. Burrough and A. Frank, Geographic Objects with Indeterminate Boundaries, Taylor \& Francis, pp. 87-94.

Varzi, A.C. (2001). Vagueness in geography. Philos. Geogr., 4(1), 4965.

Varzi, A.C. (2003). Higher-order vagueness and the vagueness of 'vague'. Mind, 112, 295-298.

Verstraete, J., de Tré, G., de Caluwe, R. and Hallez, A. (2005). Field based method for the modelling of fuzzy spatial data, in F. Petry, V. Robinson and M. Cobb, Fuzzy Modeling with Spatial Information for Geographic Problems, Springer, pp. 41-69.

Williamson, T. (1994). Vagueness, Routledge.

Wood, J. (1996a). Scale-based characterisation of digital elevation models, in D. Parker, Innovations in GIS 3, Taylor \& Francis, pp. 163-175.

Wood, J. (1996b). The Geomorphological Characterisation of Digital Elevation Models, Ph.D. Dissertation, University of Leicester, Leicester, UK.

Wood, J. (2006). Landserf: Visualisation and analysis of terrain models. http://www.soi.city.ac.uk/ jwo/landserf/.

Wright, C. (1992). Is higher order vagueness coherent? Anal., 52, 129-139.

Zadeh, L.A. (1965). Fuzzy sets. Inf. Control, 8, 338-353. 